\title{
Scintimetric assessment of synovitis activity during treatment with disease modifying antirheumatic drugs
}

\author{
NIELS OLSEN, ${ }^{1}$ POUL HALBERG, ${ }^{2}$ OLE HALSKOV ${ }^{2}$ AND \\ MICHAEL W BENTZON
}

From the ${ }^{1}$ Department of Clinical Physiology and Nuclear Medicine and the ${ }^{2}$ Department of Medicine, Section of Rheumatology, Hvidovre Hospital, University of Copenhagen, and the ${ }^{3}$ Department of Biostatistics, Statens Seruminstitut, Copenhagen, Denmark

SUMMARY In a double blind trial of 36 patients with rheumatoid arthritis a new scintimetric method was applied to three comparable patient groups before and after eight months' treatment with levamisole, penicillamine, or azathioprine. Technetium- $99 \mathrm{~m}$ pyrophosphate scintigraphy of both hands was performed on a gammacamera with a computer attached, immediately after the administration of the tracer. The uptake ratio of each proximal interphalangeal (PIP) joint and the mid-half of the adjacent proximal phalanx was calculated from the activity counted for one minute. A scintimetric index was expressed as the sum of eight uptake ratios. This index was higher for each of the three patient groups before start of treatment than that for 10 age matched controls. After eight months of treatment the index, the number of PIP joints with clinical signs of synovitis, and the total circumference of the PIP joints decreased in the penicillamine and azathioprine groups. The scintimetric method reliably reflected local synovitis activity and its changes but, like grip strength and PIP circumference, was not a representative measure of the overall activity of the disease.

Key words: medical treatment, radiology, radionuclide imaging, rheumatoid arthritis.

Clinical assessment of synovitis activity in patients with rheumatoid arthritis (RA) is difficult. Joint scanning by means of radioisotopes, which is one of several alternative methods of measuring synovitis activity, has been used with varying success for more than 20 years. $^{1}$

Scintimetric assessments of the response of treatment with disease modifying antirheumatic drugs (DMARDs) have been attempted previously in a few open trials. ${ }^{2}$ In the present study a new scintimetric method was evaluated. Repeated quantitative joint scintigraphies were performed in a controlled, double blind, comparative trial of levamisole, penicillamine, and azathioprine given to patients with RA and active synovitis. The results of the scintimetries were compared with serial clinical, biochemical, and radiological measurements of synovitis activity and the progression of structural joint damage assessed radiologically. At the same

Accepted for publication 19 April 1988.

Correspondence to Dr Niels Olsen, Frydendalsvej 1, DK-1809 Frederiksberg C, Denmark. time joint scintimetries were performed in a group of age matched controls.

\section{Subjects and methods}

Fifty nine patients who entered the study fulfilled the criteria of the American Rheumatism Association for the diagnosis of $\mathrm{RA},{ }^{4}$ as well as at least three of the following four criteria for active synovitis ${ }^{5}$ : (a) three or more swollen joints; (b) six or more tender joints; $(c)$ morning stiffness of at least 45 minutes' duration; $(d)$ erythrocyte sedimentation rate (ESR) of at least $30 \mathrm{~mm} / \mathrm{h}$. The exclusion criteria were as follows: functional class IV $^{6}$; age of 16 years or less; pregnancy or intention to become pregnant; concurrent diseases with poor prognosis as far as life is concerned; and treatment with levamisole, penicillamine, azathioprine, chloroquine, gold salts, cyclophosphamide, or glucocorticoids within the past three months. Ten age matched controls had joint scintigraphy performed because of fractured femoral necks. None of them had a history of joint disease or clinical signs of joint 
abnormalities in their hands. All patients and controls gave informed consent to the study, which was approved by the local ethical committee.

The controlled study of the effect of levamisole (150 mg daily), penicillamine (600 $\mathrm{mg}$ daily), and azathioprine $(2.5 \mathrm{mg} / \mathrm{kg}$ daily) was designed as a controlled, comparative, double blind study of eight months' duration with an open therapeutic control, as previously described. ${ }^{7}$ Ibuprofen was the only non-steroidal anti-inflammatory drug permitted. The patients were allocated to treatment with one of the three DMARDs by means of a 'minimisation technique'. ${ }^{8}$ Table 1 lists the patients on whom joint scintigraphy was performed, and Table 2 gives their characteristics at the start of the trial. The patients were examined before the start of treatment with DMARDs (month 0) and after eight months of treatment (month 8).

Articular scintigraphy of the eight ulnar proximal interphalangeal (PIP) joints was performed after intravenous injection of ${ }^{99 \mathrm{~m}} \mathrm{Tc}$ stannopyrophosphate (5.55 MBq/kg body weight; Hoechst). An image of both hands was obtained by placing their volar sides on top of a gammacamera (General Electric Radi Camera II) equipped with a low energy, parallel

Table 1 Patients with rheumatoid arthritis allocated to receive levamisole, penicillamine, or azathioprine, drop outs, and patients finally studied

\begin{tabular}{|c|c|c|c|}
\hline & $\begin{array}{l}\text { Levami- } \\
\text { sole }\end{array}$ & $\begin{array}{l}\text { Penicil- } \\
\text { lamine }\end{array}$ & $\begin{array}{l}\text { Azathio- } \\
\text { prine }\end{array}$ \\
\hline Patients allocated to the study & 20 & 19 & 20 \\
\hline Scintimetry not obtainable & 4 & 4 & 3 \\
\hline $\begin{array}{l}\text { Treatment discontinued before the } \\
\text { end of the observation period }\end{array}$ & 7 & 3 & 2 \\
\hline Patients studied & 9 & 12 & 15 \\
\hline
\end{tabular}

hole collimator during the initial 20 minutes and subsequently summarising the counts on a $256 \times 256$ ? matrix using a $16 \mathrm{~K}$ digital computer (Fig. 1). $\mathrm{A}=$ square corresponding to the visually evaluated contour of a given PIP joint was drawn on thee oscilloscope with a light pen, and, similarly, an areaํㅡ. of the same size was outlined on the shaft of the adjacent proximal phalanx (Fig. 1). The uptake ratio of each PIP joint was calculated as the ratio of the activities counted for one minute in the two areas 15 minutes after injection. A total index wascalculated as the sum of the eight uptake ratios forw each subject. The reproducibility of the method wast evaluated by repeated measurements performed withọ an interval of 48 hours in nine patients with RA.

The clinical evaluations of synovitis activity wereperformed by the same experienced rheumatologis at months 0 and 8 . The numbers of swollen ande tender, non-swollen joints were counted (all swolleno joints were also tender, but some joints were tender without being swollen). Morning stiffness was re-0 corded in quarters of an hour. The intensity of join pain was graded by a visual analogue scale, ${ }^{,}$the grip strength of both hands was measured by a sphygmo: manometer, and the total circumference of the eight ulnar PIP joints by a strain gauge. ESR and seristro albumin were measured at months 0 and 8 .

Radiograms of both hands and wrists we्fer obtained at months 0 and 8 and evaluated in twos ways - namely, (a) by indexing the radiograms af months 0 and 8 according to the method of Larsen $e$ e $a l^{10}$; and $(b)$ by comparing each of the following 320 joints at months 0 and 8 in order to register the joints in which the erosive changes had been pro은 gressing $^{7}$ : the proximal interphalangeal, metacarpo phalangeal, carpometacarpal, carpal, radiocarpal居 and radioulnar joints.

CALCULATIONS AND STATISTICS A comparison of scintimetric ratios of clinically.

Table 2 Characteristics before treatment of the patients studied and of their controls

\begin{tabular}{|c|c|c|c|c|}
\hline & Levamisole & Penicillamine & Azathioprine & Controls \\
\hline Number & 9 & 12 & 15 & \\
\hline Age (years) & $65(47-73)^{*}$ & $68(40-77)$ & $60(37-75)$ & $62(46-75)$ \\
\hline Men/women & $3 / 6$ & $4 / 8$ & $6 / 9$ & $0 / 10$ \\
\hline Duration of RA (years) & $6(<1-33)$ & $6(<1-53)$ & $15(<1-35)$ & \\
\hline Swollen joints (No) & $8(4-16)$ & $9(5-12)$ & $10(2-20)$ & \\
\hline Tender joints (No) & $19(10-33)$ & $25(9-38)$ & $29(11-49)$ & \\
\hline Morning stiffness (quarters of an hour) & $8(3-14)$ & $7(4-13)$ & $6(2-20)$ & \\
\hline $\operatorname{ESR}(\mathrm{mm} / \mathrm{h})$ & $64(32-120)$ & $48(12-87)$ & $50(13-120)$ & \\
\hline Functional class V/IVIII (No) & $0 / 6 / 3$ & $0 / 7 / 5$ & $0 / 8 / 7$ & \\
\hline Erosive disease (No) & 7 & 11 & 13 & \\
\hline \multicolumn{5}{|c|}{$\begin{array}{l}{ }^{*} \text { Values are numbers or the median (range). } \\
\text { No significant differences between the four groups of subjects }(p \geqslant 0 \cdot 10) \text {. }\end{array}$} \\
\hline
\end{tabular}




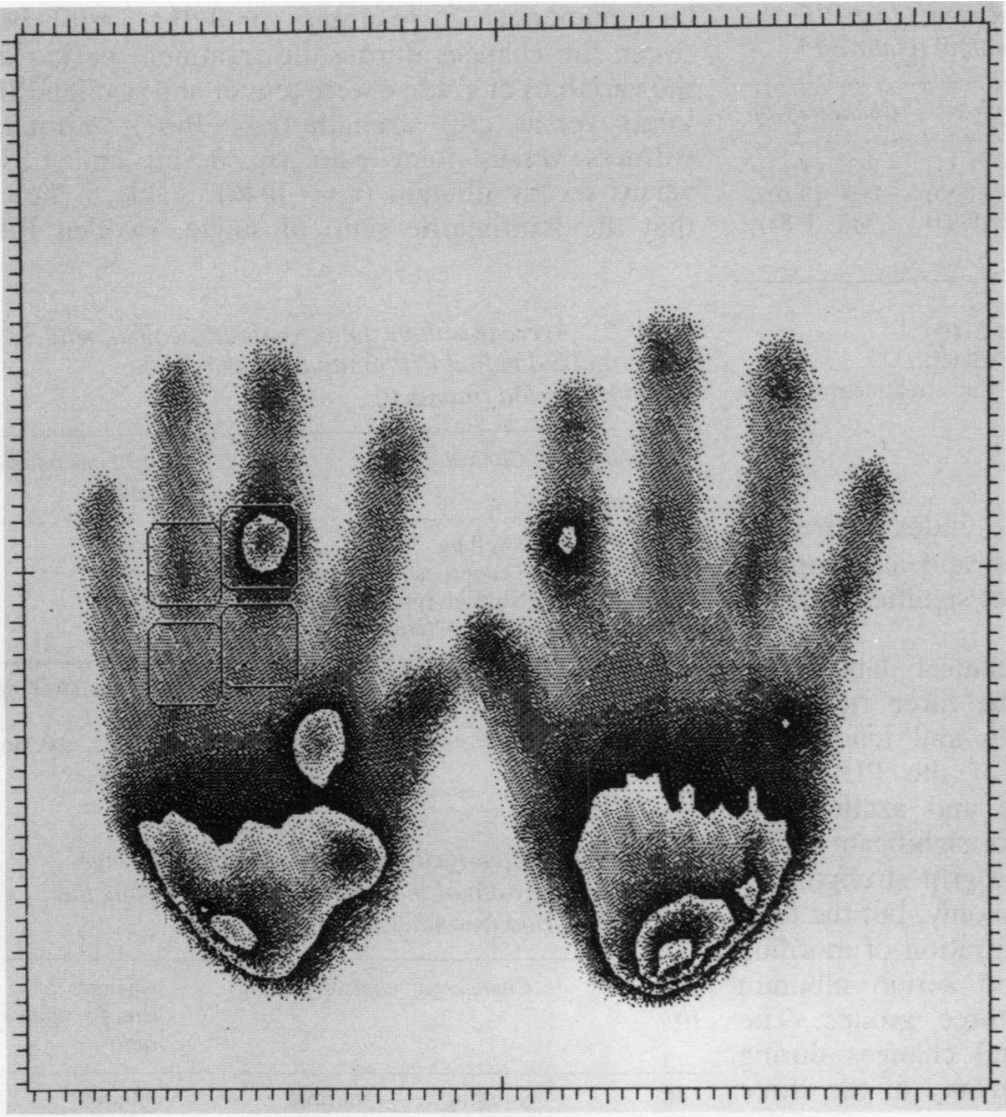

Fig. $1 A^{99 m} T c$ stannopyrophosphate scintigram of both hands in a patient with rheumatoid arthritis. The radioactivity was accumulated during the initial 20 minutes after injection and graded by means of a grey colour scale. The proximal interphalangeal joints of the right middle and ring finger were swollen and normal respectively. Equal sized regions of interest were placed over the proximal interphalangeal joint and the mid-half of the adjacent proximal phalanx to measure the uptake ratio.

different PIP joints at month 0 was performed as follows: (a) the average of scintimetric ratios in each patient was calculated for clinically swollen, tender, and normal PIP joints respectively; (b) the difference between each two of these three averaged ratios was estimated in each patient; (c) when all patients were considered this difference was statistically regarded as a difference between two related samples. Similarly, a comparison of scintimetric findings of clinical changes in PIP joints from month 0 to month 8 was based on the estimated average of paired differences of scintimetric ratios in PIP joints showing the same clinical change in a given patient. This statistical use of averaged ratios and averaged differences of ratios was found to give no bias in sampling and thus allows comparisons between two related samples, but may weaken the power of the applied Wilcoxon test.

Statistical evaluation was performed by nonparametric statistics with a significance limit of 0.05 (two sided). The differences in nomimal values between two independent samples was tested with the Fisher exact probability test. The difference in numerical values between two related samples was tested with the Wilcoxon matched pairs signed rank test. The difference in numerical values between independent samples was tested with the KruskalWallis test, followed by the Mann-Whitney rank sum test if the Kruskal-Wallis test showed significant differences. Correlations were tested by means of Spearman's rank correlation coefficient, $r_{s}$. Standard deviations are given for descriptive purposes only.

\section{Results}

The reproducibility of the uptake ratio, expressed as $1 \mathrm{SD}$ in percentage of average scintimetric ratio, was $10 \%$. Similarly, the reproducibility of the total index was $4 \%$. Table 3 shows that the index values were significantly higher at month 0 in each of the three treatment groups than in the control group. After 
Table 3 Isotope 'activity' index of the eight ulnar PIP joints before (month 0 ) and after (month 8) treatment

\begin{tabular}{lrlll}
\hline Group & No & Month 0 & Month 8 & Change (8-0) \\
\hline Levamisole & 9 & $8.28(1.68)^{*} \dagger$ & $7.91(1.11)$ & $-0.37(1.13)$ \\
Penicillamine & 12 & $9.19(1.79) \dagger$ & $8.39(1.36)$ & $-0.80(0.80) \ddagger$ \\
Azathioprine & 15 & $8.13(1.13) \dagger$ & $7.52(0.82)$ & $-0.61(0.82) \ddagger$ \\
Controls & 10 & $7.29(0.30)$ & & \\
\hline
\end{tabular}

*Values are given as the mean (SD).

†Significantly different from controls $(p<0.05)$.

$\ddagger$ Significant change during treatment $(p<0.02)$.

No significant differences between the treatment groups $(\mathrm{p}>0.05)$.

eight months of treatment the index decreased significantly in the penicillamine and azathioprine groups, but the decrease was not significant in the group receiving levamisole.

Table 4 shows the average clinical, laboratory, and radiological variables of the three treatment groups. The number of swollen and tender PIP joints and the circumference of the PIP joints decreased in the penicillamine and azathioprine groups, but the decrease was not significant in the group receiving levamisole. The grip strength improved in the azathioprine group only, but the total number of swollen joints, the duration of morning stiffness, joint pain, ESR, and serum albumin improved significantly in all three groups. The deterioration of the radiological changes during treatment was not significant in any of the three treatment groups.

No significant correlations were found between the changes during the treatment period of the scintimetric index and the clinical, laboratory, or radiological changes $\left(r_{S}<0 \cdot 25, p>0 \cdot 10, n=36\right)$. The best numerical correlations $(p<0.01, n=36)$ between the changes during the treatment period of the variables of Table 4 were tender and swollen PIP joints versus grip strength $\left(r_{S}=-0.47\right)$, morning $\stackrel{\oplus}{\stackrel{P}{?}}$ stiffness versus joint pain $\left(r_{S}=0.51\right)$, and ESR을 versus serum albumin $\left(r_{s}=-0 \cdot 46\right)$. Table 5 shows $\frac{\bar{c}}{\bar{c}}$ that the scintimetric ratio of single, swollen PIP

Table 5 Average isotope uptake ratio of swollen, tender, or normal individual PIP joints at the start of the treatment period (month 0 )

\begin{tabular}{llll}
\hline $\begin{array}{l}\text { PIP joints } \\
(\text { No })\end{array}$ & Clinical findings & $\begin{array}{l}\text { Isotope uptake } \\
\text { ratio }\end{array}$ \\
\hline 65 & Swelling & $1.33^{*}$ & 1.09 \\
85 & Tenderness without swelling & $0.92 \dagger$ & 0 \\
138 & Normal (patients with RA) & $0.91 \dagger$ & c \\
80 & Normal (controls) & 0.91 \\
\hline
\end{tabular}

*Significantly different from 'tenderness without swelling, $(\mathrm{p}<0.01)$.

†Significantly different from tenderness without swelling $(\mathrm{p}<0.05)$.

Table 6 Changes of clinical findings and of average isotope uptake ratio of individual PIP joints during the treatment period (month 8-0)

\begin{tabular}{lll}
\hline $\begin{array}{l}\text { PIP joints } \\
\text { (No) }\end{array}$ & Changes of clinical findings & $\begin{array}{l}\text { Changes of } \\
\text { isotope uptake } \\
\text { ratio }\end{array}$ \\
\hline 40 & Swelling $\rightarrow$ normal & $-0.21^{*}$ \\
27 & Swelling $\rightarrow$ tenderness & $-0.18^{*}$ \\
74 & Tenderness $\rightarrow$ normal & $-0.08 \dagger$ \\
113 & Unchanged normal & 0.01 \\
\hline
\end{tabular}

${ }^{*}$ Significant change of isotope uptake ratio $(p<0.01)$. † Significant change of isotope uptake ratio $(p<0.05)$.

Table 4 Variables other than the isotope activity index before (month 0 ) and after (month 8) treatment*

\begin{tabular}{|c|c|c|c|c|c|c|}
\hline \multirow[t]{2}{*}{ Variable } & \multicolumn{2}{|c|}{ Levamisole $(n=9)$} & \multicolumn{2}{|c|}{ Penicillamine $(n=12)$} & \multicolumn{2}{|c|}{ Azathioprine $(n=15)$} \\
\hline & Month 0 & Month 8 & Month 0 & Month 8 & Month 0 & Month 8 \\
\hline $\begin{array}{l}\text { Tender and swollen PIP joints (No) } \\
\text { Circumference of eight PIP joints (mm) } \\
\text { Grip strength (right + left hand) (mmHg) } \\
x \text { Ray changes of the hands (score) } \\
\text { Erosive changes of eight PIP joints (score) } \\
\text { Swollen joints of the body (No) } \\
\text { Morning stiffness (quarters of an hour) } \\
\text { Pain (visual analogue scale) } \\
\text { Erosive changes of } 34 \text { joints (score) } \\
\text { ESR (mm/h) } \\
\text { Serum albumin ( } \mu \text { moll) }\end{array}$ & $\begin{array}{l}4 \cdot 1 \\
470 \\
44 \cdot 7 \\
3 \cdot 1 \\
0 \cdot 35 \\
8 \cdot 8 \\
9 \cdot 0 \\
6 \cdot 3 \\
0 \cdot 62 \\
69 \\
438\end{array}$ & $\begin{array}{l}2 \cdot 1 \\
466 \\
52 \cdot 4 \\
2 \cdot 7 \\
0 \cdot 61 \\
3 \cdot 9 \dagger \\
0.9 \dagger \\
2 \cdot 3 \dagger \\
0 \cdot 70 \\
33 \dagger \\
515 \dagger\end{array}$ & $\begin{array}{l}4 \cdot 3 \\
471 \\
43 \cdot 3 \\
2 \cdot 6 \\
0 \cdot 97 \\
8 \cdot 9 \\
7 \cdot 8 \\
5 \cdot 9 \\
0 \cdot 96 \\
51 \\
483\end{array}$ & $\begin{array}{c}2.6 \dagger \\
462 \dagger \\
43.6 \\
2.8 \\
1.06 \\
4.7 \dagger \\
1.1 \dagger \\
3.0 \dagger \\
1.03 \dagger \\
29 \dagger \\
525 \dagger\end{array}$ & $\begin{array}{c}4 \cdot 2 \\
479 \\
37 \cdot 7 \\
2 \cdot 5 \\
0 \cdot 96 \\
9 \cdot 7 \\
9 \cdot 1 \\
4 \cdot 9 \\
1 \cdot 01 \\
55 \\
436\end{array}$ & $\begin{array}{c}2.2 \dagger \\
466 \dagger \\
56 \cdot 7 \dagger \\
2.5 \\
0.96 \ddagger \\
4.1 \dagger \\
3.9 \dagger \\
3.4 \dagger \\
1.01 \ddagger \\
43 \dagger \\
523 \dagger\end{array}$ \\
\hline \multicolumn{7}{|c|}{$\begin{array}{l}\text { *Mean values are given. } \\
\text { †Significantly different from same variable at month } 0 \text { within the same treatment group }(p \leqslant 0 \cdot 05) \text {. } \\
\ddagger n=14 \text {. }\end{array}$} \\
\hline
\end{tabular}


joints significantly exceeded that of tender PIP joints without swelling. On the other hand, the scintimetric ratios of clinically normal PIP joints of patients with RA and of controls were significantly lower than those of tender PIP joints without swelling. The scintimetric ratios of clinically normal joints from patients with RA and from controls did not differ. Table 6 shows that significant correlations existed between the changes of the clinical abnormalities of single PIP joints during the treatment period and the changes of the scintimetric ratios during the same interval.

\section{Discussion}

The scintimetric procedure in the present study was designed to combine the best properties of the methods used previously. Technetium- $99 \mathrm{~m}$ pertechnetate and ${ }^{99 \mathrm{~m}} \mathrm{Tc}$ labelled phosphate compounds are the radioisotopes most frequently used in studying RA. ${ }^{1}$ The mechanisms of uptake differ between these two types of indicators. Thus the increased ${ }^{99 \mathrm{~m}} \mathrm{Tc}$ pertechnetate activity of joints of patients with RA probably reflects synovial hyperaemia, whereas the uptake of ${ }^{99 \mathrm{~m}} \mathrm{Tc}$ labelled phosphate compounds has been assumed to represent a combination of synovitis and periarticular bone affections. ${ }^{11}$ Consequently, different methods of measurement and timing have been used in previous studies. The ${ }^{99 \mathrm{~m}} \mathrm{Tc}$ pertechnetate uptake of joints has been measured as the initial uptake in the joints as a fraction of the administered dose, ${ }^{23}$ whereas the uptake of ${ }^{99 \mathrm{~m}} \mathrm{Tc}$ labelled phosphate compounds has been measured by the ratio of the joint activity and the activity of an adjacent bone two hours after injection. ${ }^{11-13}$ It has, however, recently been shown that early scintigraphies of ${ }^{99 \mathrm{~m}} \mathrm{Tc}$ pertechnetate and ${ }^{99 m} \mathrm{Tc}$ labelled phosphate compounds have identical diagnostic power. ${ }^{14}$ Therefore our study included early ${ }^{99 m} \mathrm{Tc}$ pyrophosphate scintigraphy in order to ensure optimal evaluation of synovitis activity. Technetium-99m pyrophosphate scintigraphy with measurement of the joint-bone ratio was chosen in order to make each patient his own control at each investigation, and because previous workers have found that uptake of ${ }^{99 \mathrm{~m}} \mathrm{Tc}$ pyrophosphate, expressed as a fraction of the dose administered, is an unreliable measure of synovitis activity in patients with RA. ${ }^{15}$ On the other hand, these workers also found that the joint-bone uptake was likely to be underestimated in patients with RA because not only the uptake of joints but also that of bone was increased. ${ }^{6}$ This may have influenced the accuracy of the present method. The reproducibility of the present method was found to be acceptable.

In the present study the scintimetric as well as the clinical signs of synovitis in the PIP joints decreased significantly during treatment with penicillamine and azathioprine. On the other hand, neither the reduction of the scintimetric nor the clinical synovitis activity reached levels of significance during treatment with levamisole. This discrepancy is probably explained by the small sample size of patients treated with levamisole. Previous open studies of patients with RA during treatment with penicillamine showed decreased uptake of radioisotopes as well as reduction of joint circumference and joint pain $^{2} 3$ - that is, results similar to those recorded here. No scintimetric studies of patients treated with levamisole or azathioprine have previously been published. The few and poor statistical correlations of changes of variables reflecting synovitis activity during treatment periods have been mentioned in a previous study. ${ }^{17}$

According to the present study of single PIP joints the uptake ratio before treatment and the change of the uptake ratio during treatment with levamisole, penicillamine, and azathioprine correlated significantly with the clinical findings. The unchanged and normal uptake in clinically uninvolved joints during the treatment period indicates that the uptake is not influenced by the treatment itself. The identical uptakes in joints of controls and in clinically normal joints of patients with RA indicate that the sensitivities of the scintimetry and of the clinical examination are approximately identical-that is, subclinical synovitis is not detected by scintimetry. A recent study showed no correspondence between the existence of erosive changes and the results of early or late ${ }^{99 m}$ Tc-methylene diphosphonate scintigraphy, ${ }^{18}$ which is in accordance with the present findings of early ${ }^{99 \mathrm{~m}} \mathrm{Tc}$ pyrophosphate scintimetry. This indicates that scintigraphy and scintimetry of ${ }^{99 \mathrm{~m}} \mathrm{Tc}$ labelled phosphate compounds mainly detect synovitis activity in patients with RA, whereas erosive changes, in contrast with previous assumptions, ${ }^{11}$ are only insignificantly reflected by these methods.

The PIP joints, because of their anatomy, are particularly well suited for quantitative scintigraphy, and as these joints are often affected in patients with RA the present study was limited to them. The synovitis activity of swollen or tender but not swollen PIP joints and its changes during the treatment period were objectively and reliably measured by the present scintimetric uptake ratio. Such a quantitative measurement of synovitis activity of single joints is not obtainable from radiograms or measurements of grip strength or PIP circumference. Therefore the scintimetric ratio may be of help in the evaluation of local synovitis activity and its changes during treatment as the clinical evaluation is qualitative and may be influenced by wide ranges 
of interobserver variations. As might have been expected from the clinical picture of RA no statistically significant correlation was found between the present scintimetric index of the PIP joints and the clinical signs of synovitis activity in all the accessible joints of the body. Neither did the change of clinical synovitis activity of the PIP joints, the PIP circumference, or the grip strength reflect the clinical change of synovitis activity of all joints. Thus a clinically useful method of monitoring the overall effect of treatment modalities should preferably be able to include all accessible joints. Application of the principles of the present scintimetric ratio to all scintigraphically suspected joints of the body may provide more useful information.

\section{References}

1 Wallace D J, Brachman M, Klinenberg J R. Joint scanning in rheumatoid arthritis: a literature review. Semin Arthritis Rheum 1981; 11: 172-6.

2 Sturrock R D, Nicholson R, Wojtulewski J A. Technetium counting in rheumatoid arthritis. Evaluation in the small joints of the hand. Arthritis Rheum 1974; 17: 417-20.

3 Huskisson E C, Scott J, Balme H W. Objective measurement of rheumatoid arthritis using technetium index. Ann Rheum Dis 1976; 35: 81-2.

4 Ropes M W, Bennett G A, Cobb S, Jacox R, Jessar R A. 1958 revision of diagnostic criteria for rheumatoid arthritis. Bull Rheum Dis 1958; 9: 175-6.

5 Cooperating clinics committee of the American Rheumatism Association. A seven day variability study of 499 patients with peripheral rheumatoid arthritis. Arthritis Rheum 1965; 8: 302-34.
6 Steinbrocker $\mathrm{O}$, Battermann $\mathrm{R} C$. Therapeutic criteria in rheumatoid arthritis. JAMA 1949; 140: 659-62.

7 Halberg P. Controlled, double-blind, comparative studies of $\Rightarrow$ disease modifying anti-rheumatic drugs in the treatment of $\vec{\omega}$ patients with rheumatoid arthritis. A review. Dan Med Bull 1984; 31: 391-402.

8 Taves D R, Rochester N Y. Minimization: a new method of assigning patients to treatment and control groups. Clin $\frac{\mathrm{S}}{\mathrm{S}}$ Pharmacol Ther 1974; 15: 443-53.

9 Huskisson E C. Measurement of pain. Lancet 1974; ii: 1127-31. 으

10 Larsen A, Dale K, Eek M. Radiographic evaluation of rheumatoid arthritis and related conditions by standard refer- $\vec{O}$ ence films. Acta Radiol [Diagn] (Stockh) 1977; 18: 481-91.

11 Rosenthall L, Hawkins D. Radionuclide joint imaging in the diagnosis of synovial disease. Semin Arthritis Rheum 1977; 7: $\omega$ 49-61.

12 Park H-M, Terman S A, Ridolfo A S, Wellman H N. A quantitative evaluation of rheumatoid arthritic activity with Tc99 m HEDP. J Nucl Med 1977; 18: 973-6.

13 Berry H, Barrett J J, Ford-Hutchinson A, Hamilton E B D. $\vec{N}$ Radioisotope scanning using a gamma camera. Ann Rheum Dis 1978; 37: 76-7.

14 Domljan Z, Dodig D. The value of early and late ${ }^{99 \mathrm{~m}} \mathrm{Tc}^{-} \mathrm{G}$ methylene diphosphonate scintigrams of hands in patients with rheumatoid arthritis and other inflammatory rheumatic di- seases. Z Rheumatol 1984; 43: 167-70.

15 Rosenspire K C, Kennedy A C, Russomanno L, Steinbach J, $\mathbb{D}$ Blau M, Green F A. Comparison of four methods of analysis of $\mathbb{D}$ ${ }^{99 \mathrm{~m}} \mathrm{Tc}$ pyrophosphate uptake in rheumatoid arthritic joints. J Rheumatol 1980; 7: 461-8.

16 Rosenspire K C, Kennedy A C, Steinbach J, Blau M, Green $F$ A. Investigation of the metabolic activity of bone ance rheumatoid arthritis. J Rheumatol 1980; 7: 469-73.

17 Bentzon M W, Gad I, Halberg P, Halskov O, Lorenzepव Acute phase proteins and clinical synovitis activity in patie with rheumatoid arthritis. Clin Rheumatol 1987; 6: 226-32.

18 Pitt P, Berry H, Clarke M, Foley H, Barratt J, Parsons V. Metabolic activity or erosions in rheumatoid arthritis. Anno Rheum Dis 1986; 45: 235-8. 